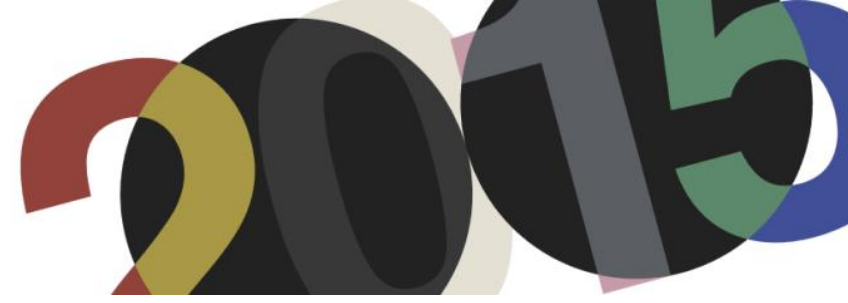

DOI: http://dx.doi.org/10.4995/LC2015.2015.1545

\title{
La poética del urbanismo de Le Corbusier: arte y función en la ciudad moderna
}

\author{
A. Soler Machado, E. Gehlen Bregolin
}

FAUFRGS

\begin{abstract}
Resumen: El objetivo de este artículo es demostrar que existe una poética en el urbanismo de Le Corbusier y que el tema se mantiene y se transforma en sus modelos teóricos y sus derivaciones. Desde el punto de vista teórico-metodológico, parte-se del presupuesto de que esa poética es el resultado de la dualidad entre arte y función presente en su pensamiento, originada en su formación personal y el momento histórico en el que produce su obra. El analisis se estructura con la agrupación de su produción urbanística en cuatro fases: 1-los años 1920: el Plan Ideal; 2-1929-38: las ciudades de América del sur y los viaductos; 3-1930-50: la Ville Radieuse; 4-Después de la Segunda Guerra Mundial: la ciudad de los $7 V$ y la Unité d'habitation. La reflexión final retoma la visión general de su produción urbanística y la vincula al concepto de utopia.
\end{abstract}

Abstract: The goal of this article is to demonstrate that there is an aspect of poetics in Le Corbusier's urbanism and that this theme is maintained and you can see it being transformed through the theoretical models and its derivations. From the methodological and theoretical point of view, we make the assumption that the poetics is the result of the duality between art and function present in his thought, which comes from the historical moment in which his work was made and from his personal background. This analysis is structured by grouping his urban planning works in for phases; the 1920s: the Ideal City; 1929-38: the cities of South America and the viaduct; 1930-50: the Ville Radieuse; after the II World War: the city of 7V and the Unite d'habitation. The final considerations bring back the general vision of his urban planning works and tie it to the concept of utopia.

Palabras clave: Le Corbusier; Urbanismo; Poética; Arte; Función. Keywords: Le Corbusier; Urbanism; Poetics; Art; Función.

\section{Introducción}

"El poeta (...) evalúa y da cuenta de la calidad duradera de las palabras. Se encuentra en el polo opuesto de las calculadoras y sigue la curva ondulante de las pasiones. Además de la utilidad, se da cuenta de lo imperecedero - el hombre". Le Corbusier ${ }^{1}$

El urbanismo de Le Corbusier está teñido de las diferentes visiones de la modernidad arquitectónica expresadas en su obra. Tiene ecos de su postura idealista y de todas sus experiencias, cada una de ellas un aprendizaje, consciente o no, registrado en bocetos, fotografías, escritos, pinturas, esculturas y proyectos. Todo lo que hizo en la vida se convirtió en materia prima de su trabajo futuro.

Su concepción de la ciudad moderna divide las opiniones. Por un lado, es vista como un esqueleto sin carne, un estricto sistema teórico racional, funcional y científico, en el que todas las relaciones son abstractas y se reducen a la cantidad. Por otro lado, "la ciudad de Le Corbusier es cualquier cosa menos un discurso científico. Es una

\footnotetext{
${ }^{1}$ Le Corbusier: "Por una Arquitectura". São Paulo: Editora da Universidade de São Paulo, 1973. p. 7.
} 
imagen completa, totalmente trabajada en cada detalle. (...) ¿sería ella científica, neutral y refutable o artística, ideológica e irrefutable? Todo apunta a la segunda interpretación",2.

El objetivo de este artículo es demonstrar que existe una poética en el urbanismo de Le Corbusier y que el tema se mantiene y se transforma en los modelos teóricos (propuestas ideales sobre terrenos hipotéticos) y en sus derivaciones: adecuaciones de los modelos a situaciones geográficas y culturales específicas.

La hipótesis que se quiere explicitar es que la tensión establecida entre la doble dimensión, funcional y artística de su urbanismo resulta en una poética: por definición, un replanteamiento semántico de ciertos elementos con aspectos metafísicos - intentos para describir los fundamentos, condiciones, leyes, estructura básica, significado y propósito de la realidad en su conjunto o de los seres en general; creación, crítica o defensa de la realidad.

Desde el punto de vista teórico-metodológico, se parte del presupuesto de que la dualidad de su pensamiento se deriva del momento histórico en el que su obra se produce y de su formación personal: en La Chaux de Fonds, donde nació, en París, donde vivió desde los 29 años, en sus lecturas y viajes.

El análisis se estructura con la agrupación de la producción urbanística de Le Corbusier en cuatro fases que corresponden a diferentes posturas urbanísticas: 1-los años 1920: el Plan Ideal; 2-1929-38: las ciudades de América del sur y los viaductos; 3-1930-50: la Ville Radieuse; 4-Después de la Segunda Guerra Mundial: la ciudad de los 7V y la Unité d'habitation.

La reflexión final retoma la visión general de su producción urbanística y la vincula al concepto de utopía.

\section{De la dualidad del pensamiento corbusiano}

El pensamiento de Le Corbusier toma forma en su tierra natal, después en París, a partir de los 29 años y en sus viajes. Le Corbusier nació en La Chaux-de-Fonds, el 06/10/1887, época en la que la ciudad se convirtió en un ambiente de talleres pequeños, y sus relojes ganaron reconocimiento internacional. De la familia calvinista, recibió una educación moral que acentuaba los contrastes entre el bien y el mal. Con el padre relojero, realizó paseos por la región, explotando la flora y la geología, y aprendiendo la lógica de los relojes, en la que cada parte cumple una función. Con la madre pianista, desarrolló su sensibilidad poética.

Con L'Eplattenier, en la École d'Art, aprendió la doctrina religiosa artesanal de Ruskin, a abstraer las estructuras de la naturaleza y a pensar en la creación natural como revelación de un orden espiritual que se debe trasladar al design $^{3}$. Conoció el movimiento arts and crafts y las teorías del ornamiento de Owen Jones, originadas en una tradición que pensaba en términos de un significado contingente y no universal, y que buscaba una renovación de la arquitectura por medio del ornamiento y de la artesanía. Más tarde se aparta de esa visión, acercándose a una concepción universalista de la arquitectura ${ }^{4}$. A partir de la historia de la región del Jurá, hecha de sendas revoluciones, políticas y religiosas, Le Corbusier construye un pedigree para sí mismo: una tradición de pensamiento libre 5 .

A los 29 años, Charles-Édouard Jeanneret hace de Paris su morada espiritual, donde continúa su aprendizaje y adopta su nuevo nombre: Le Corbusier. Sus numerosos viajes por Europa y el mundo le posibilitan hacer

\footnotetext{
${ }^{2}$ Colqhoun, Alan: "Modernidad y tradición clásica". São Paulo: Cosac 7 Naify, 2004. pp. 113-117.

${ }^{3}$ Curtis, William: "Le Corbusier: ideas and forms". London: Phaidon, 1986. p. 19.

${ }^{4}$ Colqhoun, Alan: “Modernidad y tradición clásica”. São Paulo: Cosac 7 Naify, 2004. pp. 102-103.

${ }^{5}$ Curtis, William: "Le Corbusier: ideas and forms". London: Phaidon, 1986. p. 19.
} 
contacto con la historia y aportan lo esencial para su formación. Sus croquis y acuarelas registraran su observación de elementos del pasado, de lo típico detrás del incidente, y preocupaciones morales convertidas en geometrías según su propia terminología. Si los ornamentos podían ser microcosmos, más adelante en su vida, cuadros, edificios y planes urbanos también podrían serlo ${ }^{6}$. Del 1907 al 1912, hace contacto con tres tipos de escenarios: los centros de la cultura, de la industria y del folclore ${ }^{7}$. Como Proust, sus recuerdos se mezclan con sus vivencias y proyectos.

El momento histórico en el que produce su obra también es importante para entender su pensamiento. Se caracteriza por la ruptura de la arquitectura con las demás artes y por su enlace con la ciencia y las dinámicas sociales, un cambio que comienza en los siglos XVIII y XIX, cuando la arquitectura queda dividida en sus funciones constructivas y científicas y sus funciones artísticas y de representación, siendo la razón reservada a la primera y la emoción a la última. Con el crecimiento del utilitarismo, la razón científica queda dirigida cada vez más a la eficacia instrumental ${ }^{8}$. Por ende, el funcionalismo, con sus dos tradiciones, el a priori y lo empírico, se convierte en el medio por el cual la vanguardia de los años 1920, a la que se vincula Le Corbusier, combate el historicismo.

El pensamiento de Le Corbusier contiene, pues, de un lado las preocupaciones científicas del funcionalismo; de otro, la tradición racional, moralizante y didáctica del clasicismo francés. A partir de esa dualidad, construyó sus fundamentos teóricos, los más elaborados del movimiento moderno. Encuanto que para Gropius la teoría era lo instrumental y el diseño su producto directo, para Le Corbusier la teoría era su justificación ${ }^{9}$.

En Por una arquitectura, Le Corbusier intenta una conciliación entre idealismo y racionalismo constructivo, estableciendo la distinción entre la ingeniería y la arquitectura: según el mismo, el ingeniero provee lo que es útil, muestra el camino de la verdad; el arquitecto despierta la emoción, torna la verdad palpable ${ }^{10}$. Al discutir la estética, la divide entre lo espiritual, - lo que agrada a la gente culta: la armonía y la proporción -, y lo sensorial, lo que agrada a las personas simples: la decoración y el color ${ }^{11}$.

La dualidad de su pensamiento se expresa en su obra por medio de la tensión entre el sólido y el vacío, la luz y la sombra, el movimiento horizontal y el vertical, los elementos del pasado y de la era de máquina. En el urbanismo, se revela en cuatro fases que corresponden a diferentes posturas a ser examinadas a continuación. Esa tensión es lo que genera su poética.

\section{Las cuatro fases del Urbanismo de Le Corbusier}

\subsection{Los Años 1920: El Plan Ideal}

Esta fase se caracteriza por la búsqueda de un Plan Ideal racionalista como solución a los problemas urbanos de la nueva sociedad industrial, capaz de mejorar los individuos y regular el comportamiento humano, dando lugar a una era de armonía.

\footnotetext{
${ }^{6}$ Curtis, William: "Le Corbusier: ideas and forms". London: Phaidon, 1986. p. 24.

${ }^{7}$ Cohen, Jean-Louis: "Le Corbusier 1887-1965: El lirismo de la arquitectura en la era mecánica”. Madrid: Tasken, 2009. p. 7.

${ }^{8}$ Colqhoun, Alan: "Modernidad y tradición clásica”. São Paulo: Cosac 7 Naify, 2004. pp. 69-72.

${ }^{9}$ Colqhoun, Alan: "Modernidad y tradición clásica". São Paulo: Cosac 7 Naify, 2004. p. 99.

${ }^{10}$ Colqhoun, Alan: "Modernidad y tradición clásica". São Paulo: Cosac 7 Naify, 2004. p. 106.

${ }^{11}$ Colqhoun, Alan: "Modernidad y tradición clásica". São Paulo: Cosac 7 Naify, 2004. p. 107.
} 
En los años 1920, Le Corbusier sintetiza las ideas de sus años de formación en un vocabulario personal arraigado en las condiciones de la sociedad industrial, cuyo contenido simbólico era la creación de un nuevo modelo de vida $^{12}$. Para Le Corbusier, la era maquinista exigía la superación de la pequeña construcción privada. El nuevo desafío era pensar el habitar a escala colectiva de la ciudad y del territorio. El desarrollo de la ciencia y de la técnica, del principio del siglo XX, ofrecía la posibilidad de reencuentro con las leyes perennes de la belleza ideal y de atender en una nueva escala a la necesidad del máximo rendimiento - funcional y emocional - de la ciudad y de la casa.

Le Corbusier era simpatizante de la tendencia cultural iniciada en fines del siglo XIX, direccionada a romper con el pasado por medio de la industria y el arte de vanguardia, la práctica, la eficacia, la concepción austera, racional y universal de belleza, el orden y la geometría: la llamada utopía del futuro, definido por Choay como urbanismo progresista ${ }^{13}$. Unido a los constructivistas rusos y sus propuestas utópicas, y a Gropius con respecto a sus ideas de la vivienda mínima, adhiere al funcionalismo substituyendo los criterios anteriores de la ciudad jardín por las ideas de la Cité Industrielle de Garnier.

La idea del Plan Ideal nace de su visión, idealista y pragmática: la definición de los tipos ideales era el camino para la transformación de las estructuras urbanas incompatibles con el nuevo ambiente económico y social industrial caracterizado por la presencia de la fábrica y sus sectores de vivienda. La vida moderna, relacionada a las necesidades colectivas exigía un nuevo plan, generado por una nueva concepción de la vivienda colectiva formada por la suma de células individuales. En un texto de 1952, "El regalo de las técnicas" Le Corbusier declara que la casa, - ahora con servicios que muestran el grado de civilización, es el punto de partida y fin último de la urbanística ${ }^{14}$.

La metáfora mecanicista y artística de la máquina de habitar en conjunto con la posibilidad de industrialización de la arquitectura genera la noción de standard y de la casa como principio formador de la ciudad-máquina. Los dos conceptos convergen para la noción de zonificación funcional en escalas distintas, de la casa a la ciudad. Su concepción del espacio mínimo desarrollado en el esquema Dom-inó y en el Pabellón de 1925, y la concomitante redefinición de los servicios domésticos, desplazados de la esfera individual a la colectiva, originaran el Immeuble-Villa, un superbloque semejante a un hotel, a partir del cual Le Corbusier propone la Ville Contemporaine, su primer modelo teórico de ciudad, una propuesta ideal sobre un sitio hipotético y plano.

En el Salón de Otoño de 1922, el organizador Marcel Temporal le pide a Le Corbusier que le diseñe una fuente. El acepta la propuesta con la condición de que en torno de ella se ubique una ciudad de tres millones de habitantes, la solución teórica para los problemas de París de la primeira post-guerra: vivienda en gran escala, espacios abiertos, centro de negocios y tránsito. Eso no es una broma, sino la historia que expone la ansiedad de Le Corbusier por exponer sus nuevas concepciones urbanas, aprovechando al máximo la oportunidad que se le presentaba.

Su concepción de La Ville Contemporaine de 1922 es un collage de ideas y contradicciones: incluye las ideas positivistas de una nueva sociedad, de St. Simon, la sociología newtoniana de Fourier y principios de Provenzal: el ideal de la belleza como expresión de la mente y del espíritu y no de los sentidos físicos ${ }^{15}$; y la concepción de la arquitectura a la escala del pensamiento -- lugar de lo colectivo --, y no sólo a la escala del cuerpo humano,

\footnotetext{
${ }^{12}$ Curtis, William: "Le Corbusier: ideas and forms". London: Phaidon, 1986. p. 60.

${ }^{13}$ Choay, François: "El Urbanismo”. São Paulo: Ed. Perspectiva, 1979. p. 160.

${ }^{14}$ Monteys, Xavier: "La gran máquina: la ciudad en Le Corbusier”. Barcelona: Ediciones del Serbal, 1996. pp. 11-12.

${ }^{15}$ Colqhoun, Alan: "Modernidad y tradición clásica". São Paulo: Cosac 7 Naify, 2004. p. 101.
} 
lugar pasajero en el que el individuo abriga su existencia ${ }^{16}$. Por otra parte, une la ideología progresista a referencias históricas: la estructura espacial centralizada, organizada en torno de las torres de planta cruciforme de 60 pisos de la Cité d'affaires, pone la modernidad industrial y la burocrática capitalista a nivel de una ley universal. Su forma urbana inspirada en la ciudad ideal de Bruno Taut contiene la cuadrícula utilitaria de Manhattan, la jerarquía clásica de París, la geometría simbólica de Pequim y de las ciudades ideales renascentistas.

Los tipos residenciales poseen referencias igualmente ambiguas, de la era industrial y de la historia: los Immeubles-Villas evocan las cabinas del transatlántico y las células monásticas de la Cartuja de Emma; y los edificios residenciales en redents se asemejan al falansterio de Fourier. La relación de la arquitectura con el paisaje, expresada en la línea de recorte de las masas edificadas contra el cielo, es tanto una reinterpretación de su visualización de las torres verticales de las mezquitas de Istambul en el horizonte, registrada en bocetos, cuanto la representación de una unidad cósmica y de un optimismo ingenuo respecto de las potencialidades del mundo industrial. La zonificación rígida convive con la libertad de las Unidades Vecinales de 400 por 400 metros de lado, dotadas de áreas verdes, servicios y equipamientos de uso colectivo, y de un sistema jerarquizado de vías de acceso elevadas sobre un parque continuo ${ }^{17}$. Aunque exista un enfoque humanista, la Ville se concentra más en los aspectos relativos al sistema de movimientos: a la circulación y a la velocidad.

El Plan Voisin, 1925, es la aplicación del esquema de la Ville Contemporaine a la región central de París, entonces con tres millones de habitantes. El plan se concentra en la orilla derecha del rio Sena y tiene los mismos principios y contradicciones que la Ville Contemporaine, presentados ahora, de manera aún más impactante. La demolición de gran parte del centro de París para la implantación de la grilla ortogonal que estructura sus torres y redents, y el mantenimiento de los principales monumentos históricos como objetos de una exposición contra el fondo de la arquitectura moderna, representan el conflicto entre modernidad y tradición.

Desde el punto de vista del tráfico, el plan pone al coche como la salvación de la metrópoli demoliendo la propia metrópoli. Le Corbusier se justifica con el argumento del mejoramiento de tráfico de París, lo que aumenta el valor de la tierra y fomenta a los inversores extranjeros a establecerse allí. Esa intervención pretensiosa y audaz, incompatible con la urbanidad mixta y la complejidad social de la ciudad que el mismo tanto admiraba ${ }^{18}$, no es aceptada, pero Le Corbusier logra su principal ambición en relación al plan: enunciar los problemas urbanos de París - el tráfico y la inadecuación de la vivienda y del sector administrativo - a través de sus ideas formales y de su postura innovadora de que la concentración y la densificación en altura de los edificios son el requisito previo para el progreso cultural. El Plan Voisin abre la oportunidad de discutir la planificación urbana racionalizada en gran escala, normalizada en 1928, cuando Le Corbusier funda el CIAM con Gropius, Karl Moser y Sigfried Giedion.

\footnotetext{
${ }^{16}$ Martins, Carlos: "Una Lectura Critica de Precisiones". En: Le Corbusier: Precisiones sobre un estado presente de la arquitectura y del urbanismo. São Paulo: Cosac \& Naify, 2004. p. 276.

${ }^{17}$ Monteys, Xavier: "La gran máquina: la ciudad en Le Corbusier”. Barcelona: Ediciones del Serbal, 1996. pp. $42-48$.

${ }^{18}$ Curtis, William: "Le Corbusier: ideas and forms". London: Phaidon, 1986. p. 65.
} 


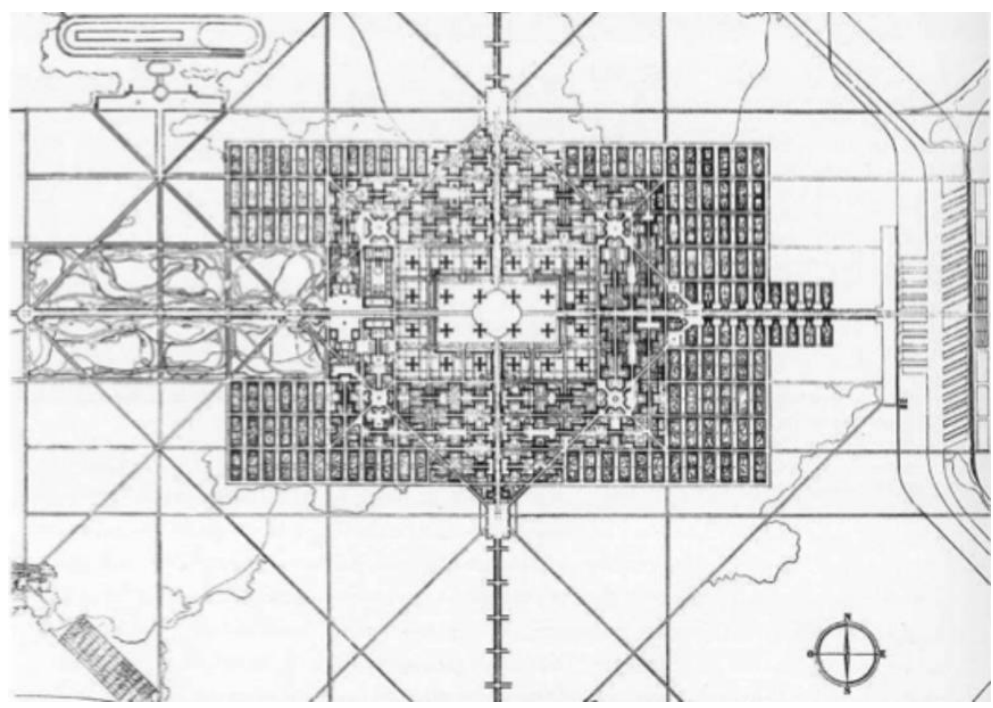

1. Le Corbusier, Ville Contemporaine, $1922^{19}$.

\subsection{9-38: las ciudades de América del Sur y los viaductos}

Esa fase marca un giro importante en su sensibilidad y visión de mundo. Invitado por los intelectuales argentinos a dar conferencias sobre diversos temas, y seducido por la inminente construcción de una nueva capital para Brasil, Le Corbusier conoce la región entre el Rio de la Plata y el sureste de Brasil en 1929.

En el vuelo entre Buenos Aires y Asunción, mira el paisaje desde una nueva perspectiva: el avión cambia radicalmente su percepción de las ciudades y del mundo, aumentando su comprensión a cerca de las escalas de la arquitectura y las formas de la naturaleza ${ }^{20}$. El avión es también un símbolo de la teoría de la visión general, una noción hegeliana en la que el poeta-filósofo es capaz de entender toda la historia y ver en ella la operación de la razón. El contexto cósmico avistado en el vuelo, de pliegues y ondulaciones, se tradujo en la "teoría del meandro," en el concepto de una "quinta fachada" y en una nueva propuesta urbana: el edificio-viaducto, una estructura que contiene fracciones de su repertorio, como autopistas, rascacielos y líneas de vivienda.

Si el propósito funcional del mega-edificio era resolver el aumento de la población y facilitar el flujo de personas y mercancías por los puntos de salida de la ciudad, su propósito artístico se expresó en la audacia de la inmensa escultura sobre el paisaje sinuoso, haciendo referencia tanto al "Roadtown," como al Lingotto de Turín. Los viaductos gigantescos que resolverían todos los problemas relacionados con la zonificación, la circulación, la preservación y expansión de las ciudades de América del Sur se mantuvieron sólo en sus bocetos, pero demuestran su nueva sensibilidad a las condiciones geográficas y culturales locales.

\footnotetext{
${ }^{19}$ Le Corbusier: "Le Grand”. London: Phaidon, 2014. p.130.

${ }^{20}$ Cohen, Jean-Louis: “Le Corbusier 1887-1965: El lirismo de la arquitectura em la era mecânica”. Madrid: Tasken, 2009. p. 11.
} 
La atmósfera de descubrimientos, junto con su talento mágico de metamorfosear el mundo, de acuerdo a sus propias fantasías, dio lugar a las intervenciones urbanas de Montevideo, Sao Paulo, Río de Janeiro y después en $\operatorname{Argel}^{21}$. En Montevideo y Sao Paulo los viaductos se convierten en ejes y su intersección establece el sector de negocios de la ciudad (Cité d'affairs). Las propuestas de Río de Janeiro, donde el viaducto gana la topografía peculiar a través de curvas y túneles, tiene sus legados brasileros: los edificios de vivienda "Pedregulho" y "Gávea" de Affonso Eduardo Reidy, son fragmentos de esta ciudad lineal de Le Corbusier. Las ideas, los planes y las historias experimentadas en este viaje, como el encuentro con la cantante estadounidense Josephine Baker, a bordo del transatlántico Giulio Cesare hacia Buenos Aires, compiladas en Précision, produjeron una gran influencia en su trabajo futuro.

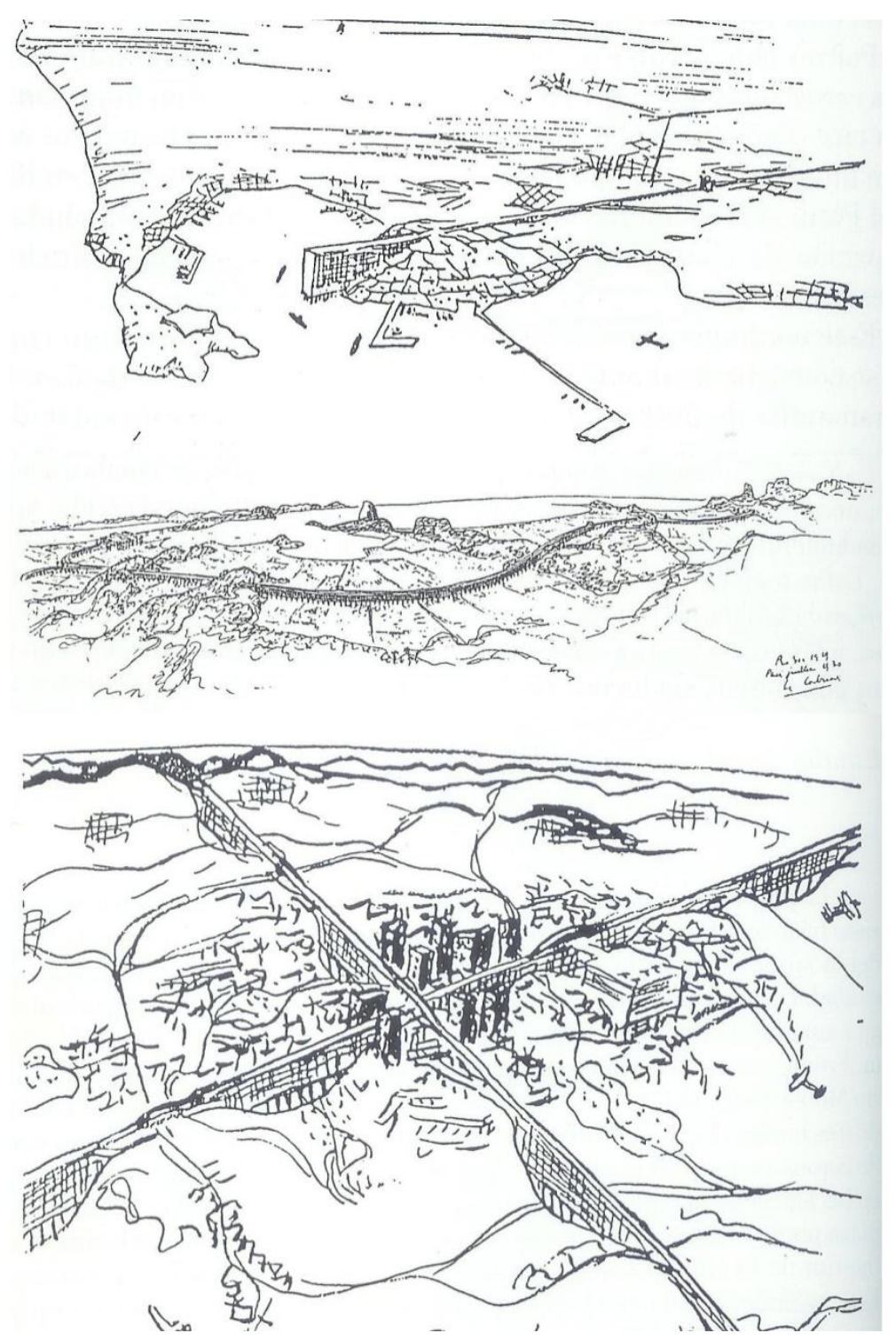

2. Le Corbusier, Propuestas para Río de Janeiro, Montevideo y Sao Paulo, $1929^{22}$.

\footnotetext{
${ }^{21}$ Curtis, William: "Le Corbusier: ideas and forms". London: Phaidon, 1986. p. 123.

${ }^{22}$ Monteys, Xavier: "La gran máquina: la ciudad en Le Corbusier”. Barcelona: Ediciones del Serbal, 1996. pp. 182, 178 y 180.
} 


\subsection{0-50: la Ville Radieuse}

Esa fase se caracteriza por el desarrollo de la nueva sensibilidad respecto a los lugares y la historia adquirida por Le Corbusier en el viaje por América del Sur, expresada en la formulación de un nuevo modelo teórico caracterizado por la humanización del programa original racionalista: la Ville Radieuse, el modelo de referencia de la mayor parte de su obra urbana, que abarca un período desde 1930 hasta la Segunda Guerra Mundial.

Le Corbusier no cambia sus antiguas convicciones, sino que revela una cierta desilusión con la máquina, con las promesas de los tiempos modernos y los ideales estilísticos previstos en la década de 1920, sustituyendo la creencia en el triunfo de la era maquinista por el deseo de un futuro menos doctrinario, donde sería posible la convivencia entre técnicas primitivas y avanzadas.

La sensibilidad del fin del ensueño, es una sensibilidad que acepta y celebra el artificio, la máscara, la convención, el territorio secreto, la ilusión, la contradicción y la complejidad, la grieta y el fragmento, la ironía y la paradoja.

La Ville Radieuse, el segundo modelo teórico de Le Corbusier, diseñado entre 1924 y 1935, es una respuesta a las acusaciones de Moscú de que sus planes anteriores eran mecanismos capitalistas. El plan es una evolución de la Ville Contemporaine, donde intenta lograr un equilibrio entre los órdenes, individual, familiar y público; entre la forma construida y el espacio abierto; y entre la ciudad y la naturaleza ${ }^{23}$.

Su esquema antropomórfico diseñado a partir de dos mallas giradas a 45 grados, formada por líneas de uso paralelas inspiradas en el modelo racional de Ciudad Lineal de Nikolay Alexandrovich Milyutin, evita cualquier núcleo de poder central y es expandible: la metáfora perfecta para el desarrollo de una sociedad igualitaria donde se elimina la diferencia entre el campesinado y el proletariado.

Tipológicamente, los bloques en redents de la Ville Radieuse representan una mejora en comparación con el modelo anterior, haciendo más evidente la relación entre la casa y el hombre. Su visión de que la ciudad arranca del hogar, es la más antropológica y tal vez la más humana de entre sus contemporáneos ${ }^{24}$.

En esta etapa, Le Corbusier proyecta 13 ciudades, donde demuestra la capacidad de adaptación de los modelos, de la Ville Radieuse - y los viaductos, en el caso de Argel - a las circunstancias geográficas y culturales específicas.

El sector de negocios (Cité d'affaires) se hace cada vez más independiente en las propuestas que siguen y, con el tiempo, Le Corbusier llega a reconocer el papel de la antigua ciudad como el centro, al que se unen otros componentes. Los medios de transporte también se someten a cambios.

Las estaciones puestas simbólicamente cerca del centro de negocios, en las primeras propuestas, se desplazan, en las siguientes, a las zonas de servicio. La industria presente en la periferia de la Ville Contemporaine y de la Ville Radieuse, abandona la ciudad y se instala en las rutas de conexión.

En las ciudades ubicadas en la orilla de un lago o mar, la Cité d'affaires se ubica siempre a su lado (Argel, Barcelona, Ginebra, Río de Janeiro, Buenos Aires y Nemours).

\footnotetext{
${ }^{23}$ Curtis, William: "Le Corbusier: ideas and forms". London: Phaidon, 1986. p. 119.

${ }^{24}$ Monteys, Xavier: “La gran máquina: la ciudad en Le Corbusier”. Barcelona: Ediciones del Serbal, 1996. p. 16.
} 
Los principios de la Ville Radieuse se aplican en 1930, en el plan de Moscú, Rusia; en 1932, en el Plan Maciá de Barcelona, España y en el plan de Ginebra, Suiza; en 1933, en los planes de Estocolmo, Suecia y Amberes, Bélgica; en 1934, en el plan de Nemours, Argelia; en 1935, en los planes de Nueva York, EE.UU., Roma, Italia y Zlin, República Checa; en 1936, en los planes de Hellocourt, Francia y Addis Abeba, Etiopía; y en 1937, en el nuevo plan de París, Francia.

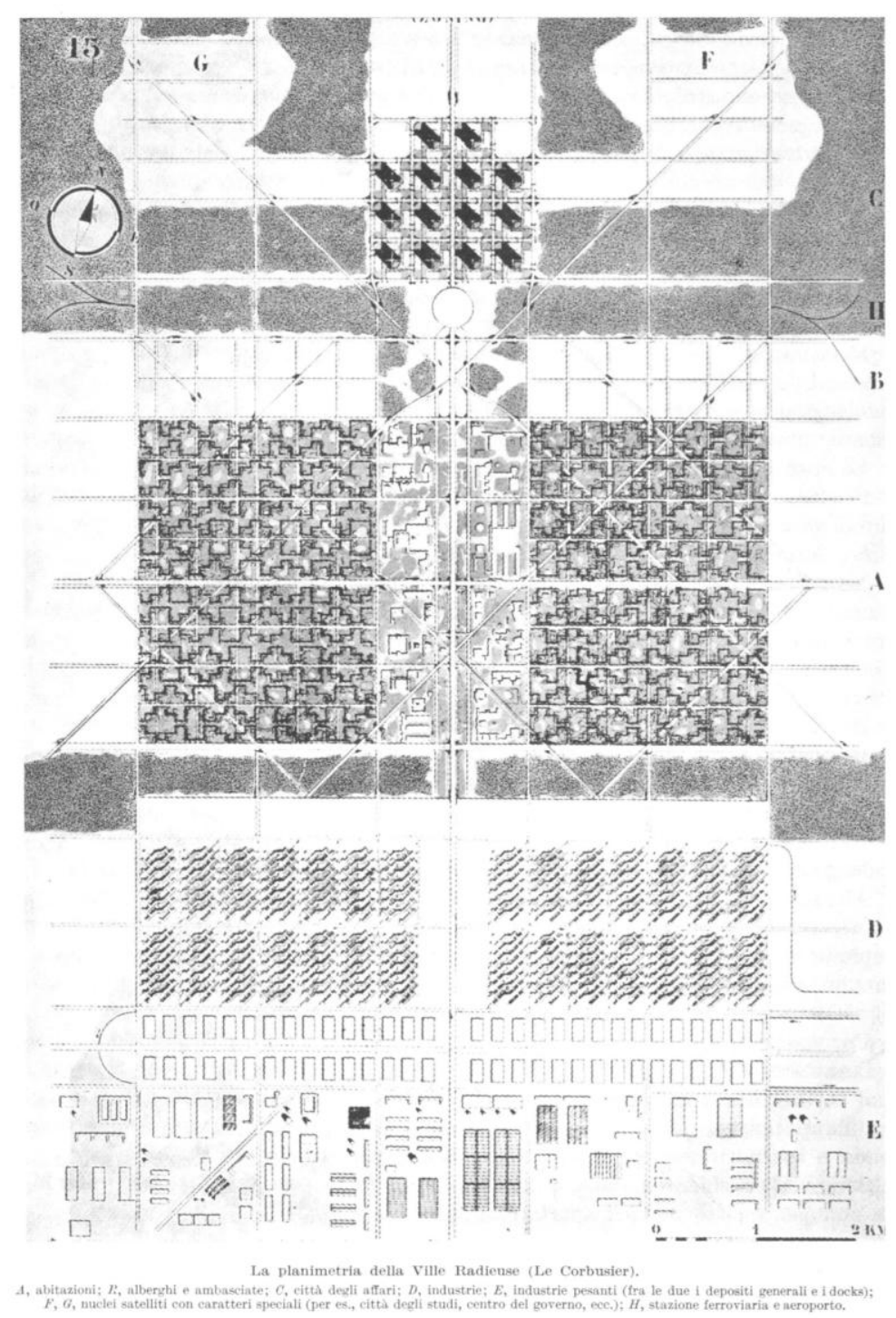

3. Ville Radieuse, $\operatorname{Plan}^{25}$.

\footnotetext{
${ }^{25}$ Monteys, Xavier. "La gran máquina: la ciudad en Le Corbusier”. Barcelona: Ediciones del Serbal, 1996. p. 40.
} 


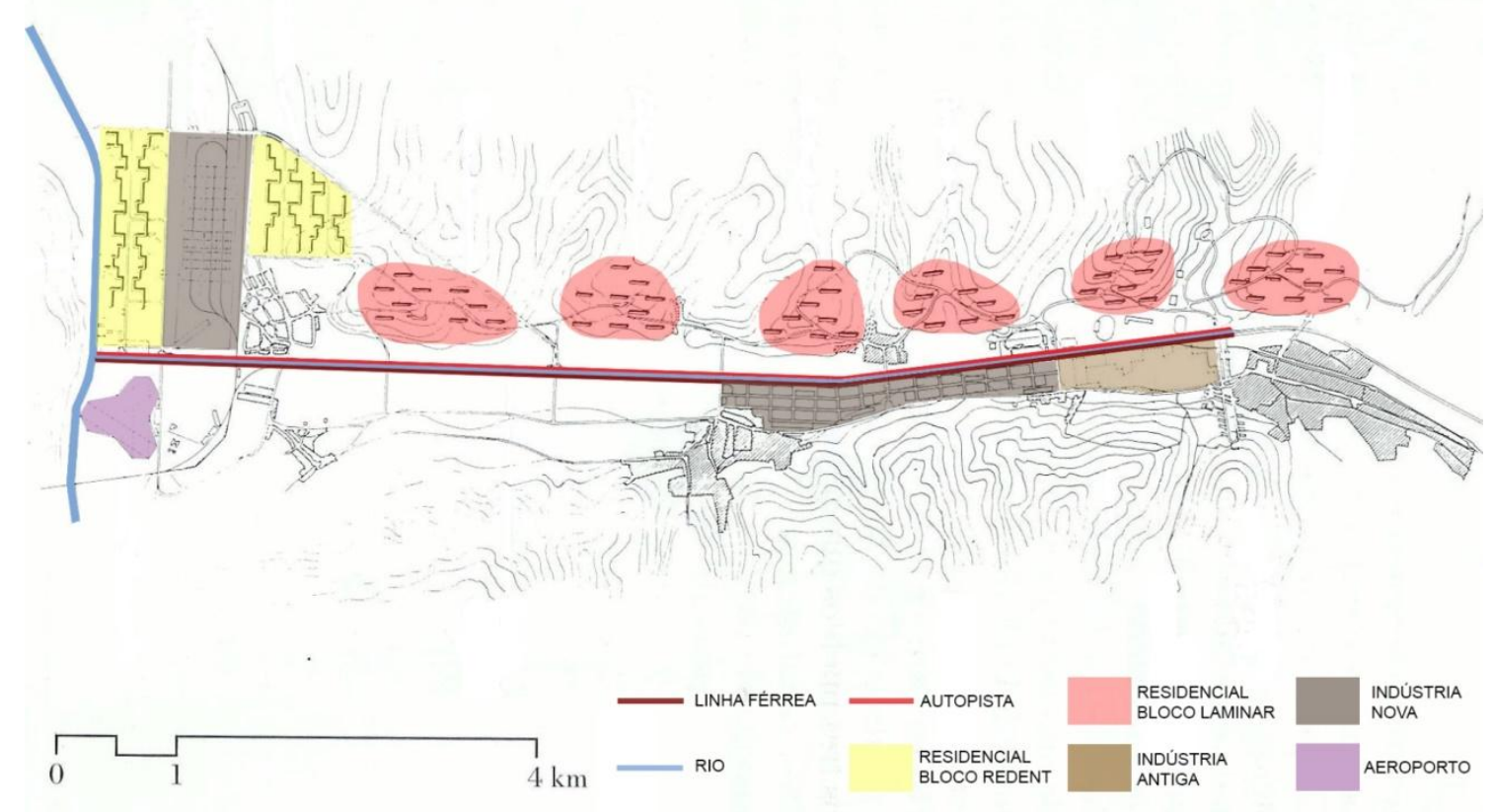

4. Le Corbusier, Plan de Zlin, $1935^{26}$.

De 1930 a 1942, Le Corbusier trabaja en el Plan Obus, haciendo la transposición de los principios de la Ville Radieuse y de la propuesta de Río de Janeiro a un contexto específico, geográficamente similar a la capital carioca: un rango estrecho, emparedado entre el mar y las montañas, donde era necesario hacer hincapié en la idea de crecimiento orgánico.

En el plan para Argel, capital de Argelia, la idea de ciudad lineal con viaductos se expresa en cuatro elementos principales, orquestados de manera escultórica: la Cité d'affaires; el conjunto de apartamentos curvados de clase media alrededor del Fuerte de L'Empereur; la alta ruta que une a estos dos elementos al casco antiguo colonial; y un enorme viaducto por sobre una ruta que se extiende a lo largo de la costa.

El Plan Obus es, quizás, su proyecto urbano con más contenido artístico y poético: la malla rígida anterior reemplazada por una abstracción de las curvas femeninas de la mujer brasileña, y del paisaje montañoso de Río, expresa la magia fructífera y sensual de Argelia y evoca tanto la caligrafía mística de sus bocetos, cuanto las paredes onduladas de las terrazas de Favre-Jacot, planeadas veinte años antes.

La poética está presente en el nombre mismo del plan: "Obus" significa cáscara explosiva y la propuesta recuerda la trayectoria curva de un proyectil que se choca con la curva de la costa, y que estalla en fragmentos alrededor de las colinas y el casco antiguo ${ }^{27}$.

La estrategia revela un arquitecto interesado en la cuestión del contexto y en las condiciones humanas en diferentes circunstancias. Pero, paradójicamente, expresa. tanto la idea social utópica de la fusión del hombre con la naturaleza, como la idea de una sociedad elitista. Las diversas versiones presentadas fueron consideradas poco realistas y rechazadas.

\footnotetext{
${ }^{26}$ Monteys, Xavier: "La gran máquina: la ciudad en Le Corbusier”. Barcelona: Ediciones del Serbal, 1996. p. 238 y análisis de los autores.

${ }^{27}$ Curtis, William: "Le Corbusier: ideas and forms". London: Phaidon, 1986. p. 123.
} 

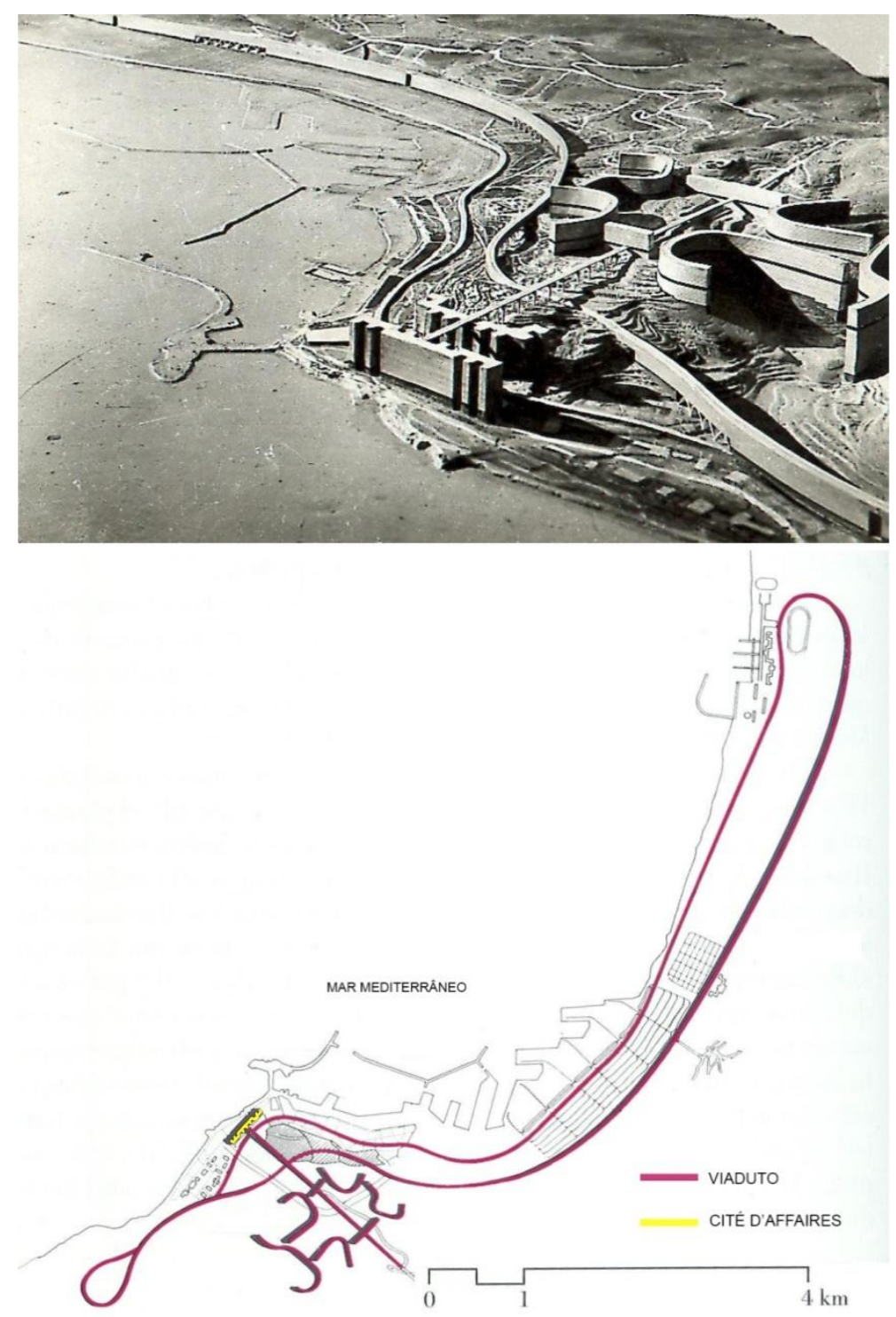

5. Le Corbusier, Plan de Argel, $1942^{28}$.

\subsection{Después de la Segunda Guerra Mundial: la ciudad de las $7 \mathrm{~V}$ y la Unité d'habitation}

La obsesión de Le Corbusier con respecto a la fabricación de la vivienda en serie encuentra en la Europa de la post-guerra, en la cual la necesidad de viviendas alcanzó un nivel sin precedentes, un campo fértil. Al mismo tiempo, su reflexión estética se expresa ahora en forma de poema, Le Poème de l'angle droit, escrito entre 1947 e 1955. En una parte se nota su concepción cósmica y poética de la geometría:

"El universo de nuestros ojos descansan

en una bandeja del horizonte

El lado que mira hacia el cielo

\footnotetext{
${ }^{28}$ Monteys, Xavier: "La gran máquina: la ciudad en Le Corbusier”. Barcelona: Ediciones del Serbal, 1996. p. 186 y análisis de los autores.
} 
Consideremos el espacio inconcebible

Justo aqui imperceptible

Descansar se acostar dormir

- Mourir

La espalda al sol ...

Pero me levanté!

Puesto que usted tiene razón

Estás lista a los actos.

Derecho sobre la plataforma terrestre

Las cosas asombrosas usted

contracta con la naturaleza el

pacto de solidaridad: es el ángulo recto

De pie frente al mar vertical

ahí estás en tus pies ${ }^{29}$ ".

En sus últimos cinco proyectos urbanos, Le Corbusier no descarta los modelos anteriores, pero aplica su tercer modelo teórico, la Ciudad Lineal Industrial, o Regla de las 7 Vías, que surgió de la formulación de Le Trois Etablissements Humaines de 1945, donde define los tres tipos de asentamientos esenciales del hombre: la Unidad de Granja, la Ciudad Concéntrica Radiante de Intercambios y la Ciudad Lineal Industrial.

Estos planes se caracterizan por la adopción en filas alternadas de la Unité d'habitation, su última tipología de vivienda, una evolución de los tipos anteriores, cuyo aislamiento es compensado por la incorporación de los servicios urbanos ${ }^{30}$.

La comunidad ideal es una especie de síntesis de toda la obra de Le Corbusier y reafirma la dualidad entre el arte y la función, y entre referencias técnicas e históricas. La Unité es una ciudad jardín vertical y una metáfora del

\footnotetext{
${ }^{29}$ L'univers de nos yeux repose sur un plateau bordé d'horizon La face tournée vers le ciel Considérons l'espace inconcevable jusqu'ici insaisi.

Reposer s'étendre dormir

- mourir

Le dos au sol...

Mais je me suis mis debout!

Puisque tu es droit

te voilà propre aux actes.

Droit sur le plateau terrestre

des choses saisissables tu

contractes avec la nature un

pacte de solidarité : c'est l'angle droit

Debout devant la mer vertical

te voilà sur tes jambes.

Le Corbusier: "Le Poème de l'angle droit: A3 MILIEU". 1955. Disponíble en: $<$ http://www.fondationlecorbusier.fr/corbuweb/morpheus.aspx?sysId=13\&IrisObjectId=6474\&sysLanguage=frfr\&itemPos=19\&itemSort=fr-fr_sort_string $1 \% 20 \&$ itemCount=47\&sysParentName=\&sysParentId=25 $>$. Aceso en 6 jun 2015.

${ }^{30}$ Frampton, Kenneth: "História Crítica da Arquitetura Moderna”. São Paulo: Martins Fontes, 2003. p. 274.
} 
transatlántico, pero es narrativa como en el tiempo de Víctor Hugo y contiene las lecciones de Roma, registrados en sus bocetos de viaje.

Tiene la misma relación dual greco-romana de encuadramiento y destaque del paisaje, y se estructura a partir de la idea de promennade vertical que conduce a la terraza, cuyo diseño evoca los objetos del cubismo y reinterpreta tanto el Lingotto, cuanto Delfos, el circus romano, la Piazza Navona, el Foro de Pompeya y Villa Adriana. La Unité es uno de los supuestos más importantes de la cultura urbana contemporánea ${ }^{31}$.

Entre 1945 y 46, Le Corbusier elabora los planes franceses de Saint-Die, Saint-Gaudens, La Rochelle-Pallice y Marseille Vieux-Port; en 1948, el plan de Izmir, Turquía; en 1950, el plan de Bogotá, Colombia; en 1951, los planes para el sur de Marsella, Francia y Chandigarh, India; en 1956, el plan de Meaux, Francia y en 1958, el plan de Berlin Centro, Alemania.

En consonancia con otros giros y paradojas en su carrera, el mayor proyecto urbanístico de Le Corbusier se ubicaba lejos de los países industriales de Occidente: en la India, donde el clima caliente y las limitaciones de la tecnología local exigieron la adecuación de sus soluciones típicas.

Con la separación de Pakistán de la India, el estado de Punjab se divide y su capital queda en el lado paquistaní de la frontera, por lo que se hace necesario la construcción de una nueva capital a ser implantada en un punto donde la llanura empieza a doblarse, formando las bases de la cordillera del Himalaya. Chandigarh debería ser una ciudad eficiente, con espacios limpios y abiertos para liberar a los indios de la tiranía de las ciudades súper pobladas y sucias y del confinamiento de una vida en la agricultura.

En el plan de 1951, la organización formal básica con retícula ortogonal y carreteras axiales, sigue el esquema de la Ville Radieuse, con el Capitolio - abrigo de la democracia - materializando la cabeza de la figura antropomorfa, en lugar de los rascacielos del modelo ${ }^{32}$. La jerarquía de calles de diferentes tamaños en función de su uso, creando los sectores rectangulares de las comunidades urbanas autónomas, surge de la Regla de las $7 \mathrm{~V}$.

\section{La poética del Urbanismo de Le Corbusier}

"La ciudad es una imagen poderosa que acciona nuestro espíritu. Porque la ciudad no seria, aún hoy día, fuente de poesía". Le Corbusier ${ }^{33}$

Al articular el arte y la función, el Urbanismo de Le Corbusier constituye una poética, cuya metafísica, es una utopía ambigua: concibe el mundo moderno como un momento de retorno y prefiguración de un orden universal ideal, símbolo de nostalgia de la era histórica, pero también, de su superación por la era tecnológica en la que se confunden el progreso y el destino ${ }^{34}$.

\footnotetext{
${ }^{31}$ Monteys, Xavier: "La gran máquina: la ciudad en Le Corbusier. Barcelona: Ediciones del Serbal, 1996. p. 147.

${ }^{32}$ Curtis, William: "Le Corbusier: ideas and forms". London: Phaidon, 1986. pp. 190-194.

${ }^{33}$ Le Corbusier: "Urbanismo". São Paulo: Martins Fontes, 2011. p. VII.

${ }^{34}$ Argan, Giulio Carlo: "Proyecto y Destino”. São Paulo: Editora Ática, 2001. p. 23.
} 


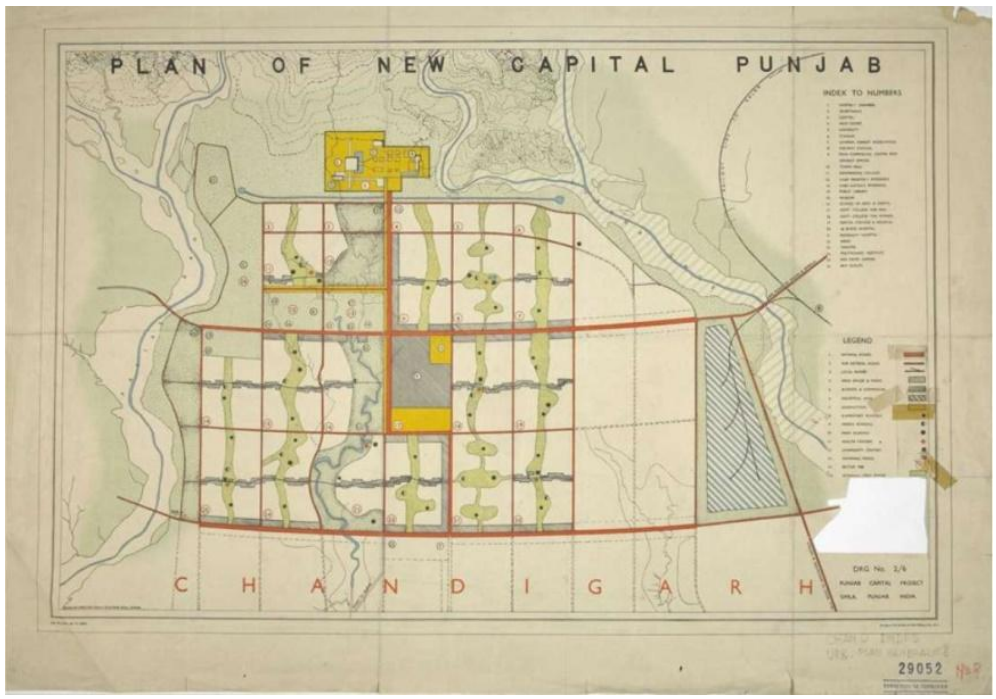

6. Le Corbusier, Plan de Chandigarh, $1956^{35}$.

Los rasgos utópicos del urbanismo corbusiano se deben a la asociación entre una organización social perfecta y un espacio nuevo de doble dimensión: una funcional, el modelo, referente a sus trazos reproducibles y una artística, el retrato, referente a sus particularidades:

"La primera imagen, que llamaré retrato porque pinta los rasgos espaciales que hacen de la Utopía una individualidad única, es el resultado, hasta en la particularidad de sus edificios, de las contingencias de su geografía y de la historia. La segunda imagen, que llamaré modelo porque conserva de la Utopía solamente características espaciales mal ubicadas y reproducibles, depende, por el contrario, sólo del orden humano y de un estricto sistema de normas culturales. Estas dos imágenes siguen siendo distintas (...), bajando de la escala del territorio a la ciudad y la casa, ${ }^{, 36}$.

El modelo es lo que sirve de objeto de imitación, corresponde a generalidades y se expresa en los conceptos y las formas de sus formulaciones teóricas (Ville Contemporaine, Ville Radieuse, Viaductos y Ciudad de las 7V). Los conceptos incluyen los ideales de universalidad, reproducibilidad y zonificación de usos; las formas, los trazados reguladores esquemáticos cartesianos con referencias de la tradición clásica francesa y la morfología abstracta que se opone a la tradición. El retrato corresponde a la adaptación y transformación de los modelos de acuerdo a contextos específicos, generando una multitud de posibilidades ilustradas por las ciudades que se presentan.

La concepción corbuseana de la ciudad como máquina habitable es tecnicista y funcional y aparentemente contraria a la concepción heideggeriana, según la cual la poesía hace el habitar ${ }^{37}$, originada en la poiésis griega, en referencia al acto poético como un momento de éxtasis, la poesía haciendo del habitar una vivienda. La técnica se deriva de téchne, que significaba "técnica" y "arte". En la era moderna, el arte se aparta de la técnica, ahora confundida con funcionalidad, un requerimiento arquitectónico que se refiere al uso -- la utilitas de Vitruvio.

\footnotetext{
${ }^{35}$ Disponible en: $<$ http://architizer.com/blog/changes-in-store-for-chandigarh/>. Acceso en 4 jun 2015.

${ }^{36}$ Choay, François: "A regra e o Modelo: Sobre a Teoria da Arquitetura e do Urbanismo". São Paulo: Editora Perspectiva, 1985. p. 153.

${ }^{37}$ Heidegger, Martin: "Poéticamente habita el hombre". 1958.

Diponible en: 〈http://olimon.org/uan/heidegger-poeticamente habita el hombre.pdf >. Acceso en: 4 jun 2015. p. 2.
} 
Le Corbusier las reúne aproximándo-se a Heidegger e incluso a Aristóteles: si la Poética del pensador griego es un conjunto de notas sobre el tema de la poesía y el arte, la poética corbuseana es el conjunto de sus obras y planes, cada cual una demonstración de la posible tensión entre el arte y la función.

La poética de su urbanismo surge de la condición transversal de su trabajo creativo, característica sobresaliente de su carrera; es una construcción intelectual hecha a partir de los vínculos establecidos entre las ideas y las imágenes, entre las artes visuales y la arquitectura, entre la historia y la modernidad, entre las vivencias y los deseos; y se traduce en modelo, metáfora y poética para pensar la ciudad. Emerge de las paradojas y contradicciones no resueltas.

Para Le Corbusier, la simple oposición entre el hombre y el poeta de la ciencia es ilusoria ${ }^{38}$. El espacio corbuseano contiene una dimensión funcional y otra artística: la concepción tecnicista del diseño urbano combinada con una visión poética del ser.

En la mayor parte de sus obras, Le Corbusier da expresión artística al conflicto entre la idea clásica de un orden ideal a priori y la noción pragmática (función) que heredó de las tradiciones historicistas y positivistas, expresadas como lo funcional, lo accidental y lo contingente ${ }^{39}$.

Le Corbusier ocupó uno de esos raros momentos en la historia en que parecía que la opinión del artista y del hombre de pasiones convergían hacia un mito colectivo, pero fue más exitoso en la conciliación de sus ideas conflictivas en sus edificios que en su teoría o en sus proyectos urbanos ${ }^{40}$.

En el Congreso CIAM de 1933, sobre el tema de la Ciudad Funcional, las ideas urbanas de Le Corbusier fueron retiradas de su visión poética original y peligrosamente aceptadas e incorporadas en la Carta de Atenas como recomendación normativa, causando un gran impacto en la planificación urbana en su conjunto y paralizando la investigación sobre otros tipos de vivienda después de la Segunda Guerra Mundial ${ }^{41}$.

El nuevo paradigma urbano que propone un nuevo orden formal del espacio social con fuertes rasgos utópicos, influye en la planificación de muchas ciudades del mundo a partir de la segunda mitad del siglo XX. En Brasil, el mejor ejemplo es el Plan Piloto de Brasilia, diseñado por Lucio Costa en 1957.

Hoy en día, las ideas de Le Corbusier, aceptadas o criticadas, pueden ser vistas como un laboratorio urbano ${ }^{42}$ y deben ser reinterpretadas pero nunca olvidadas.

\section{Agradecimientos:}

Este trabajo se realizó con el apoyo de FAPERGS.

\footnotetext{
${ }^{38}$ Colqhoun, Alan: “Modernidad y tradición clásica”. São Paulo: Cosac 7 Naify, 2004. p. 109.

${ }^{39}$ Colqhoun, Alan: "Modernidad y tradición clásica". São Paulo: Cosac 7 Naify, 2004. pp. 86-87.

${ }^{40}$ Colqhoun, Alan: "Modernidad y tradición clásica”. São Paulo: Cosac 7 Naify, 2004. pp. 122-182.

${ }^{41}$ Curtis, William: "Le Corbusier: ideas and forms". London: Phaidon, 1986. p. 122.

${ }^{42}$ Von Moss, Stanislaus: "Le Corbusier, Elements of a Syntesis". Rotterdam : 010 Publishers, 2009. Diponible en: $<$ http://books.google.com.br/books?id=X igJKO7y5kC\&pg=PA50\&hl=pt-

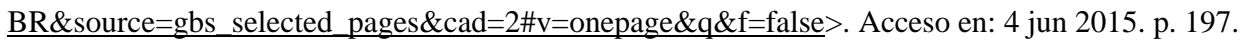




\section{Listado de las imágenes:}

1. Le Corbusier, Ville Contemporaine, 1922. Le Corbusier: Le Grand. London: Phaidon, 2014. p.130.

2. Le Corbusier, Propuestas para Río de Janeiro, Montevideo y Sao Paulo, 1929. Monteys, Xavier: "La gran máquina: la ciudad en Le Corbusier. Barcelona: Ediciones del Serbal, 1996. pp. 182, 178 y 180.

3. Le Corbusier, Ville Radieuse, Plan. Monteys, Xavier. "La gran máquina: la ciudad en Le Corbusier". Barcelona: Ediciones del Serbal, 1996. p. 40.

4. Le Corbusier, Plan de Zlin, 1935. Monteys, Xavier: "La gran máquina: la ciudad en Le Corbusier. Barcelona: Ediciones del Serbal, 1996. p. 238 y análisis de los autores.

5. Le Corbusier, Plan de Argel, 1942. Monteys, Xavier: "La gran máquina: la ciudad en Le Corbusier. Barcelona: Ediciones del Serbal, 1996. p. 186 y análisis de los autores.

6. Le Corbusier, Plan de Chandigarh, 1956. Disponible en:<http://architizer.com/blog/changes-in-store-forchandigarh/>. Acceso en 4 jun 2015.

\section{Referencias Bibliográficas:}

Argan, Giulio Carlo: “Proyecto y Destino”. São Paulo: Editora Ática, 2001.

Choay, François: “El Urbanismo”. São Paulo: Ed. Perspectiva, 1979.

Choay, François: “A regra e o Modelo: Sobre a Teoria da Arquitetura e do Urbanismo”. São Paulo: Editora Perspectiva, 1985.

Cohen, Jean-Louis: “Le Corbusier 1887-1965: El lirismo de la arquitectura en la era mecánica”. Madrid: Tasken, 2009.

Colqhoun, Alan: “Modernidad y tradición clásica”. São Paulo: Cosac \& Naify, 2004.

Curtis, William: “Le Corbusier: ideas and forms”. London: Phaidon, 1986.

Heidegger, Martin: "Poéticamente habita el hombre". 1958. Diponible en: <http://olimon.org/uan/heideggerpoeticamente habita el hombre.pdf>. Acceso en: 4 jun 2015.

Le Corbusier: "Por una Arquitectura”. São Paulo: Editora da Universidade de São Paulo, 1973.

Le Corbusier: "Urbanismo”. São Paulo: Martins Fontes, 2011.

Le Corbusier: "Le Grand”. London: Phaidon, 2014.

Frampton, Kenneth: "História Crítica da Arquitetura Moderna”. São Paulo: Martins Fontes, 2003.

Fondation Le Corbusier. Disponiblel en: <http://www.fondationlecorbusier.fr $>$. Acceso en 4 jun 2015.

Monteys, Xavier: “La gran máquina: la ciudad en Le Corbusier”. Barcelona: Ediciones del Serbal, 1996.

Martins, Carlos: "Una Lectura Critica de Precisiones". En: Le Corbusier: Precisiones sobre un estado presente de la arquitectura y del urbanismo. São Paulo: Cosac \& Naify, 2004.

Von Moss, Stanislaus: "Le Corbusier, Elements of a Syntesis". Rotterdam : 010 Publishers, 2009. Diponible en: $<$ http://books.google.com.br/books?id=X igJKO7y5kC\&pg=PA50\&hl=pt-

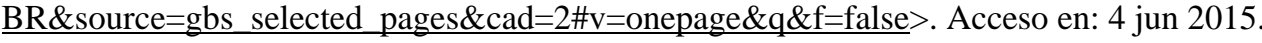

